\title{
HIC and SSC Behavior of High-Strength Pipeline Steels
}

\author{
Xian-Bo Shi ${ }^{1,2} \cdot$ Wei Yan $^{1} \cdot$ Wei Wang ${ }^{1} \cdot$ Lian-Yu Zhao $^{3} \cdot$ Yi-Yin Shan $^{1} \cdot$ Ke Yang $^{1}$
}

Received: 11 October 2014/Revised: 16 December 2014/Published online: 22 March 2015

(C) The Chinese Society for Metals and Springer-Verlag Berlin Heidelberg 2015

\begin{abstract}
In this study, hydrogen-induced cracking (HIC) and sulfide stress corrosion cracking (SSC) behaviors of highstrength pipeline steels in four different strength grades (X70, X80, X90 and X100) with the microstructure of acicular ferrite were estimated. The results showed that both of X70 and X80 steels exhibited better HIC resistance, and their susceptibility to HIC increased with the strength grade. HIC parameters, including cracking length ratio, cracking thickness ratio (CTR) and cracking sensitivity ratio, were all increased, and among these, the CTR increased most, with the increase in the strength grade. HIC was found to initiate and grow along the hard boundaries such as large size martensite/austenite (M/A) islands and bainitic ferrite. In addition, the density of hydrogen-induced blister on the steel surface was increased with the decrease in $\mathrm{pH}$ value for the same-grade pipeline steels. SSC susceptibilities of X80, X90 and X90-C were revealed to subsequently decrease, which was related to the large size M/A islands.
\end{abstract}

\section{KEY WORDS: Hydrogen-induced cracking; Sulfide stress corrosion cracking; High-strength pipeline steel;} Martensite/austenite island (M/A)

\section{Introduction}

Pipeline steels for sour oil and gas containing hydrogen sulfide $\left(\mathrm{H}_{2} \mathrm{~S}\right)$ generally suffer from either hydrogen-induced cracking (HIC) or sulfide stress corrosion cracking (SSC). Oil and gas containing high $\mathrm{H}_{2} \mathrm{~S}$ are noxious to pipeline steels because of the hydrogen-induced corrosion [1]. In recent years, driven by energy considerations, oil

Available online at http://link.springer.com/journal/40195

KeYang

kyang@imr.ac.cn

1 Institute of Metal Research, Chinese Academy of Sciences, 72 Wenhua Road, Shenyang 110016, China

2 University of Chinese Academy of Sciences, 19A Yuquan Road, Beijing 100049, China

3 PetroChina Pipeline Company, 408 Xinkai Road, Langfang 065000, China and gas reserves have been discovered under in deep waters, where the environment is more aggressive [2]. This gives rise to a demand for high-quality, special, microalloyed steels to make pipes having a good resistance to the environment at the stages of exploitation and transport of these products. Therefore, it is necessary to develop new steels in order to meet the rigorous corrosion requirements such as $\mathrm{H}_{2} \mathrm{~S}$ corrosion. It is well known that high-strengthgrade steel pipelines have to offer at least three benefits, including safety, economy and efficiency, during supplying their products to market. In addition, higher-strength-grade steels can avoid large wall thickness under in deep waters, which facilitates the pipe making process. So it is essential to develop high-strength pipeline steels with better $\mathrm{H}_{2} \mathrm{~S}$ resistance. However, it is very difficult to enhance the strength level of the pipeline steel but with no decrease in the $\mathrm{H}_{2} \mathrm{~S}$ resistance. This is a great challenge in the current research of pipeline steel. In the last two decades, much work concerning the effects of composition, microstructure and inclusions on $\mathrm{H}_{2} \mathrm{~S}$ resistance has been done [3-10]. 
Among these researches, it has been found that the acicular ferrite microstructure possesses outstanding $\mathrm{H}_{2} \mathrm{~S}$ resistance regardless of other metallurgical factors, because the fine dispersed carbonitrides and the high-density tangled dislocations in the acicular ferrite acting as the hydrogen traps [4-6].

There have been numerous efforts to improve both the strength and resistance of pipeline steels to $\mathrm{H}_{2} \mathrm{~S}$ corrosion crack in sour oil and gas environments [11-13]. However, the improvement in resistance to $\mathrm{H}_{2} \mathrm{~S}$ attack is always at the expense of strength. Hardie et al. [11] compared the hydrogen embrittlement susceptibility of three API-grade pipeline steels (X60, X80 and X100) and found that the loss of ductility companies with the increase in strength level. Arafina et al. [12] reported that the bainitic microstructure may increase the susceptibility of X80 and X100 pipeline steels to HIC. Huang et al. [13] indicated that the X120-grade pipeline steel cannot service in the sour environment due to the hard phase in microstructure. Nonetheless, the $\mathrm{H}_{2} \mathrm{~S}$ resistance of various-strength-grade pipeline steels has not been explored much. In this study, a comparison of $\mathrm{H}_{2} \mathrm{~S}$ resistance among four high-strengthgrade pipeline steels with microstructure of the acicular ferrite was investigated in terms of $\mathrm{HIC}$ and SSC susceptibilities.

\section{Experimental}

\subsection{Materials}

Five pipeline steels were employed in the present study, which were labeled as X70, X80, X90, X90-C and X100, according to the strength grade. $\mathrm{X} 90-\mathrm{C}$ is a commercial pipeline steel used in current pipeline industry. The chemical compositions of these five steels are listed in Table 1. All steels but X90-C were melted in a $25-\mathrm{kg}$ vacuum induction melting furnace and forged into blocks of $70 \mathrm{~mm} \times 70 \mathrm{~mm} \times 80 \mathrm{~mm}$. These blocks were soaked at $1200{ }^{\circ} \mathrm{C}$ for $5 \mathrm{~h}$, and then hot-rolled into plate by thermo-mechanical controlled processing (TMCP), and finally, the cooling rate was controlled by water spray. Table 2 shows the details of TMCP parameters.

\subsection{Microstructural Observation}

The microstructure was examined by scanning electron microscopy (SEM, Hitachi S-3400N) and transmission electron microscopy (TEM). Samples were mechanically ground with silicon carbide papers to No. 2000, polished and then etched in a $2 \%$ nital solution. For TEM observation, thin foils were prepared from 300- $\mu$ m-thick disks, which were firstly mechanically thinned to approximately $50 \mu \mathrm{m}$ and then electropolished by a twin-jet electropolisher in a solution of $10 \mathrm{vol} \%$ perchloric acid and $90 \mathrm{vol} \%$ ethanol. Inclusions on the surface of the polished samples were carefully observed using an optical microscope under the magnification of 100 times.

\subsection{Mechanical Properties}

The specimens for the mechanical property tests were cut from the middle of the rolled plates in the transverse direction. The tensile test was carried out at room temperature with a cross-head speed of $5 \mathrm{~mm} / \mathrm{min}$ on a SCHENCK-100KN servo-hydraulic testing machine, and Charpy impact test was conducted on sub-size specimens of $5 \mathrm{~mm} \times 10 \mathrm{~mm} \times 55 \mathrm{~mm}$ at $-20{ }^{\circ} \mathrm{C}$. The sub-zero temperature for the impact tests was controlled by liquid nitrogen.

\subsection{Hydrogen-Induced Cracking}

The HIC test was performed in accordance with NACE Standard TM 0284-2003. The specimens were $100 \mathrm{~mm}$ long and $20 \mathrm{~mm}$ wide, and the thickness was the same of the plate. Figure 1 shows the orientation of the specimen and the faces to be examined after testing. The HIC test was carried out in the solution of $5.0 \mathrm{wt} \% \mathrm{NaCl}, 0.50 \mathrm{wt} \%$ $\mathrm{CH} 3 \mathrm{COOH}$ and $94.5 \mathrm{wt} \%$ distilled water at ambient temperature and pressure, and the duration time was selected as 96 and $288 \mathrm{~h}$. Pure nitrogen gas $\left(\mathrm{N}_{2}\right)$ was applied to

Table 1 Chemical compositions of the pipeline steels (wt $\%$ )

\begin{tabular}{lllllllllllll}
\hline Steel & $\mathrm{C}$ & $\mathrm{Si}$ & $\mathrm{Mn}$ & $\mathrm{S}$ & $\mathrm{P}$ & $\mathrm{Mo}$ & $\mathrm{Cu}$ & $\mathrm{Cr}$ & $\mathrm{Ni}$ & $\mathrm{Al}$ & $\mathrm{Nb}+\mathrm{V}+\mathrm{Ti}$ & $\mathrm{Fe}$ \\
\hline X70 & 0.032 & 0.14 & 0.81 & 0.0017 & 0.0050 & 0.11 & 0.18 & 0.30 & 0.11 & 0.055 & 0.092 & Bal. \\
X80 & 0.046 & 0.14 & 1.53 & 0.0014 & 0.0050 & 0.20 & 0.31 & 0.30 & 0.10 & 0.061 & 0.132 & Bal. \\
X90 & 0.046 & 0.10 & 1.68 & 0.0013 & 0.0050 & 0.19 & 0.30 & 0.29 & 0.20 & 0.031 & 0.117 & Bal. \\
X90-C & 0.050 & 0.19 & 1.77 & 0.0016 & 0.0076 & 0.24 & 0.0086 & 0.30 & 0.016 & 0.038 & 0.089 & Bal. \\
X100 & 0.046 & 0.10 & 1.91 & 0.0013 & 0.0050 & 0.29 & 0.29 & 0.30 & 0.50 & 0.038 & 0.138 & Bal. \\
\hline
\end{tabular}


Table 2 Measured processing parameters of TMCP

\begin{tabular}{|c|c|c|c|c|c|c|c|c|c|}
\hline \multirow[t]{2}{*}{ Steel } & \multicolumn{7}{|c|}{ Temperature of different rolling steps denoted by interpass reduction } & \multirow{2}{*}{$\begin{array}{l}\text { Cooling } \\
\text { rate } \\
\left({ }^{\circ} \mathrm{C} / \mathrm{s}\right)\end{array}$} & \multirow{2}{*}{$\begin{array}{l}\text { Final cooling } \\
\text { temperature } \\
\left({ }^{\circ} \mathrm{C}\right)\end{array}$} \\
\hline & $\begin{array}{l}80-60 \mathrm{~mm} \\
\left({ }^{\circ} \mathrm{C}\right)\end{array}$ & $\begin{array}{l}60-45 \mathrm{~mm} \\
\left({ }^{\circ} \mathrm{C}\right)\end{array}$ & $\begin{array}{l}45-30 \mathrm{~mm} \\
\left({ }^{\circ} \mathrm{C}\right)\end{array}$ & $\begin{array}{l}30-24 \mathrm{~mm} \\
\left({ }^{\circ} \mathrm{C}\right)\end{array}$ & $\begin{array}{l}24-16 \mathrm{~mm} \\
\left({ }^{\circ} \mathrm{C}\right)\end{array}$ & $\begin{array}{l}16-11 \mathrm{~mm} \\
\left({ }^{\circ} \mathrm{C}\right)\end{array}$ & $\begin{array}{l}11-8 \mathrm{~mm} \\
\left({ }^{\circ} \mathrm{C}\right)\end{array}$ & & \\
\hline $\mathrm{X} 70$ & 1090 & 1045 & 986 & 909 & 850 & 841 & 815 & 16 & 430 \\
\hline $\mathrm{X} 80$ & 1100 & 1056 & 1000 & 892 & 854 & 800 & 772 & 15 & 300 \\
\hline X90 & 1079 & 1046 & 987 & 890 & 835 & 800 & 750 & 20 & - \\
\hline X100 & 1092 & 1005 & 960 & 907 & 837 & 780 & 725 & 28 & - \\
\hline
\end{tabular}

purge the residual oxygen of the airtight vessel for $2 \mathrm{~h}$ before testing, and then hydrogen sulfide $\left(\mathrm{H}_{2} \mathrm{~S}\right)$ gas was charged per $24 \mathrm{~h}$ into the solution to keep a saturated concentration. After the HIC test, the surface blistering condition was examined by SEM and energy-dispersive spectroscopy (EDS). The crack length ratio $\left(R_{\mathrm{CL}}\right)$, crack thickness ratio $\left(R_{\mathrm{CT}}\right)$ and crack sensitivity ratio $\left(R_{\mathrm{CS}}\right)$ were determined by the following equations:

$R_{\mathrm{CL}}=\frac{\sum a}{W} \times 100 \%$,

$R_{\mathrm{CT}}=\frac{\sum b}{T} \times 100 \%$,

$R_{\mathrm{CS}}=\frac{\sum(a \times b)}{W \times T} \times 100 \%$,

where $a$ is crack length (mm), $b$ is crack thickness (mm), $W$ is section width (mm), and $T$ is test specimen thickness (mm).

\subsection{Sulfide Stress Corrosion Cracking}

The dead weight-type and constant-load test according to Method A of NACE Standard TM 0177-2005 was performed to evaluate the SSC resistances of three experimental steels, $\mathrm{X} 80, \mathrm{X} 90$ and $\mathrm{X} 90-\mathrm{C}$, in the solution of $5.0 \mathrm{wt} \% \mathrm{NaCl}, 0.50 \mathrm{wt} \% \mathrm{CH} 3 \mathrm{COOH}$ and $94.5 \mathrm{wt} \%$ distilled water. The test specimens were machined according to Fig. 2, in such way that the applied tensile loading axis corresponded to the rolling direction of the rolled plates. The specimens were mounted in a cell filled with the solution and then loaded with two stress levels, 80 and $90 \%$ of yield strength, respectively. Pure $\mathrm{H}_{2} \mathrm{~S}$ gas was charged per $24 \mathrm{~h}$ into the solution to keep a saturated concentration during the testing. The test was performed under a certain stress for $720 \mathrm{~h}$, at ambient temperature, if the specimen fractured before $720 \mathrm{~h}$, and then the time-to-failure of the specimen was recorded. After then, the fracture surface of the fractured specimens was cleaned by $0.2 \%$ EDTA (ethylenediaminetetraacetic acid) solution for 3-10 min, and then observed by SEM.

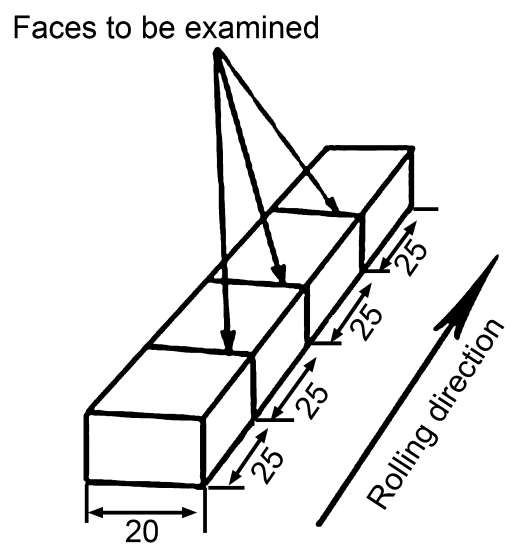

Fig. 1 Schematic diagram of the specimen for HIC test and the faces to be examined (unit: $\mathrm{mm}$ )

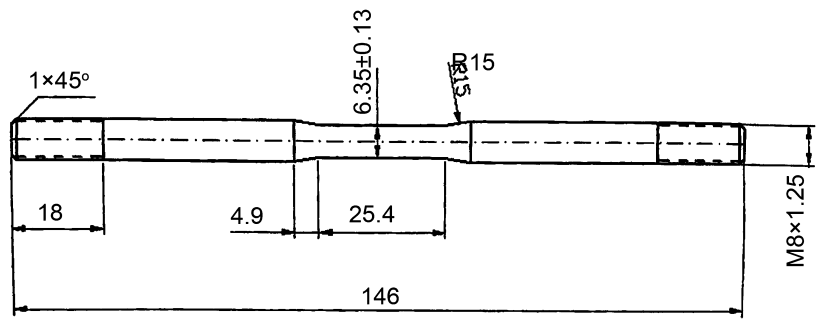

Fig. 2 Schematic diagram of the specimen for SSC test (unit: $\mathrm{mm}$ )

\section{Results}

\subsection{Microstructures and Mechanical Properties}

Microstructures of the five pipeline steels in four different strength grades, namely X70, X80, X90, X90-C and X100, were observed by SEM, as shown in Fig. 3. It can be seen that all the steels exhibit the microstructure of acicular ferrite $(\mathrm{AF})$, which consists of quasi-polygonal ferrite $(\mathrm{QF})$ and bainitic ferrite (BF) with dispersed martensite/austenite $(\mathrm{M} / \mathrm{A})$ islands in the matrix $[14,15]$. X70 shows a QFdominated microstructure plus a few polygonal ferrite (PF) with the grain size between 2 and $10 \mu \mathrm{m}$ (Fig. 3a). X80 presents a typical AF microstructure (Fig. 3b). The grain configuration is irregular, varied in the range of $1-5 \mu \mathrm{m}$ 

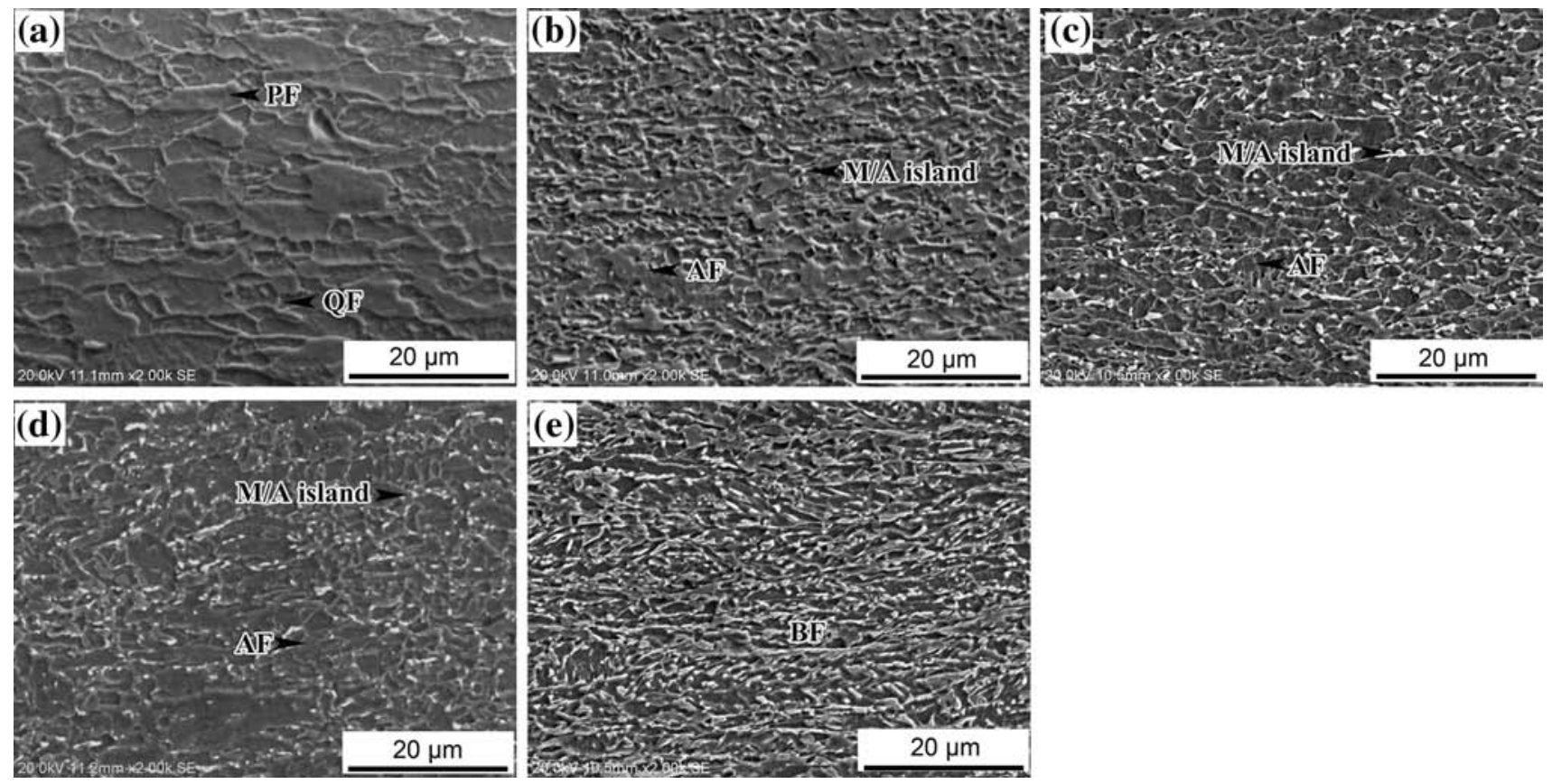

Fig. 3 SEM images of the experimental steels: a X70, b X80, c X90, d X90-C, e X100

and distributed in random orientations. The grain size of X90 is approximately $5 \mu \mathrm{m}$ (Fig. 3c). In contrast, the grain size of the commercial pipeline steel is larger than that of $\mathrm{X} 90$ while the amount of M/A island is smaller (Fig. 3d). X100 shows a BF-dominated microstructure (Fig. 3e). The BF boundary was evident along with the rolling direction, which is related to the high manganese, nickel contents and higher cooling rate. Inclusions were not found under optical microscope in the five tested steels. Mechanical properties of the experimental steels are listed in Table 3. It can be found that the strength was improved with slightly increasing the hard phase (BF). This is in agreement with the results in Refs. [16, 17]. In addition, all steels exhibited excellent impact toughness except for the steel X90-C.

\subsection{Corrosion Characteristics and Hydrogen- Induced Cracking Parameters}

Two different $\mathrm{pH}$ values and duration time were applied in the HIC test, namely standard test with the initial $\mathrm{pH}$ value of 2.7 and the final $\mathrm{pH}$ value of 3.2 for $96 \mathrm{~h}$, and severe test with the initial $\mathrm{pH}$ value of 1.9 and the final $\mathrm{pH}$ value of 3.0 for $288 \mathrm{~h}$. The macrographs of the five steels after the HIC test are shown in Fig. 4. It can be seen that for the standard test, the steels $\mathrm{X} 70, \mathrm{X} 80$ and $\mathrm{X} 90-\mathrm{C}$ exhibited excellent resistance to hydrogen-induced blistering (HIB), while a few HIBs were observed on the surfaces of the steels X90 and X100. In contrast, the density of HIB on the steel surface increased with the decrease in $\mathrm{pH}$ value and the increase in duration time for a given steel in the severe test. In addition, corrosion products were found to cover evenly on the entire surface of the conventional commercial X90C steel (Fig. 4i, k). An analysis of the steel X90-C corrosion products using the energy spectrum showed that $\mathrm{Fe}$ and $\mathrm{S}$ are present (Fig. 4l), which are in agreement with the results of Zhao et al. [18]. Furthermore, it was noted that the susceptibility to HIB increased with the strength grade of the tested steels in the severe test.

The values of $R_{\mathrm{CL}}, R_{\mathrm{CT}}$ and $R_{\mathrm{CS}}$ calculated according to Eqs. (1), (2) and (3) for the five tested steels are shown in Table 4. It was observed that the X70 and X80 steels exhibited better HIC resistance in both the standard test and severe test. For the same test condition, however, the order of HIC resistance was X70 $>$ X80 $>$ X90-C $>$ X90 $>$ X100, namely the susceptibility to HIC increases with the strength grade of the steel. In addition, the CLR, CTR and CSR all increase and the CTR increases the most with increasing of the strength grade. Under typical industrial applications, the $R_{\mathrm{CL}}, R_{\mathrm{CT}}$ and $R_{\mathrm{CS}}$ values that become 15,5 and $2 \%$ smaller, respectively, are considered as an acceptance criterion of HIC test according to Standard API 5L. As shown in Table 4, the X90-, X90-C- and X100-grade steels presented higher $R_{\mathrm{CL}}, R_{\mathrm{CT}}$ and $R_{\mathrm{CS}}$ values than this criterion limitation. Therefore, they are not suitable for sour service application.

\subsection{Hydrogen-Induced Cracking}

Figure 5 shows the SEM micrographs of the hydrogeninduced cracks in the tested steels. As mentioned above, 
Table 3 Mechanical properties of the experimental steels

\begin{tabular}{llllll}
\hline Steel & YS $(\mathrm{MPa})$ & UTS $(\mathrm{MPa})$ & Ratio of YS/UTS & Elongation $(\%)$ & Impact toughness $(\mathrm{J})$ \\
\hline X70 & 491 & 563 & 0.87 & 25.0 & $106^{\mathrm{a}}$ \\
X80 & 620 & 720 & 0.86 & 23.5 & $116^{\mathrm{a}}$ \\
X90 & 657 & 729 & 0.90 & 23.5 & $116^{\mathrm{a}}$ \\
X90-C & 690 & 926 & 0.95 & 20 & $57^{\mathrm{b}}$ \\
X100 & 698 & 922 & 0.76 & 21.5 & $104^{\mathrm{a}}$ \\
\hline
\end{tabular}

a Impact sample size is $5 \mathrm{~mm} \times 10 \mathrm{~mm} \times 55 \mathrm{~mm}$, testing temperature is $-20{ }^{\circ} \mathrm{C}$

b Impact sample size is $5 \mathrm{~mm} \times 10 \mathrm{~mm} \times 55 \mathrm{~mm}$, testing temperature is $0{ }^{\circ} \mathrm{C}$
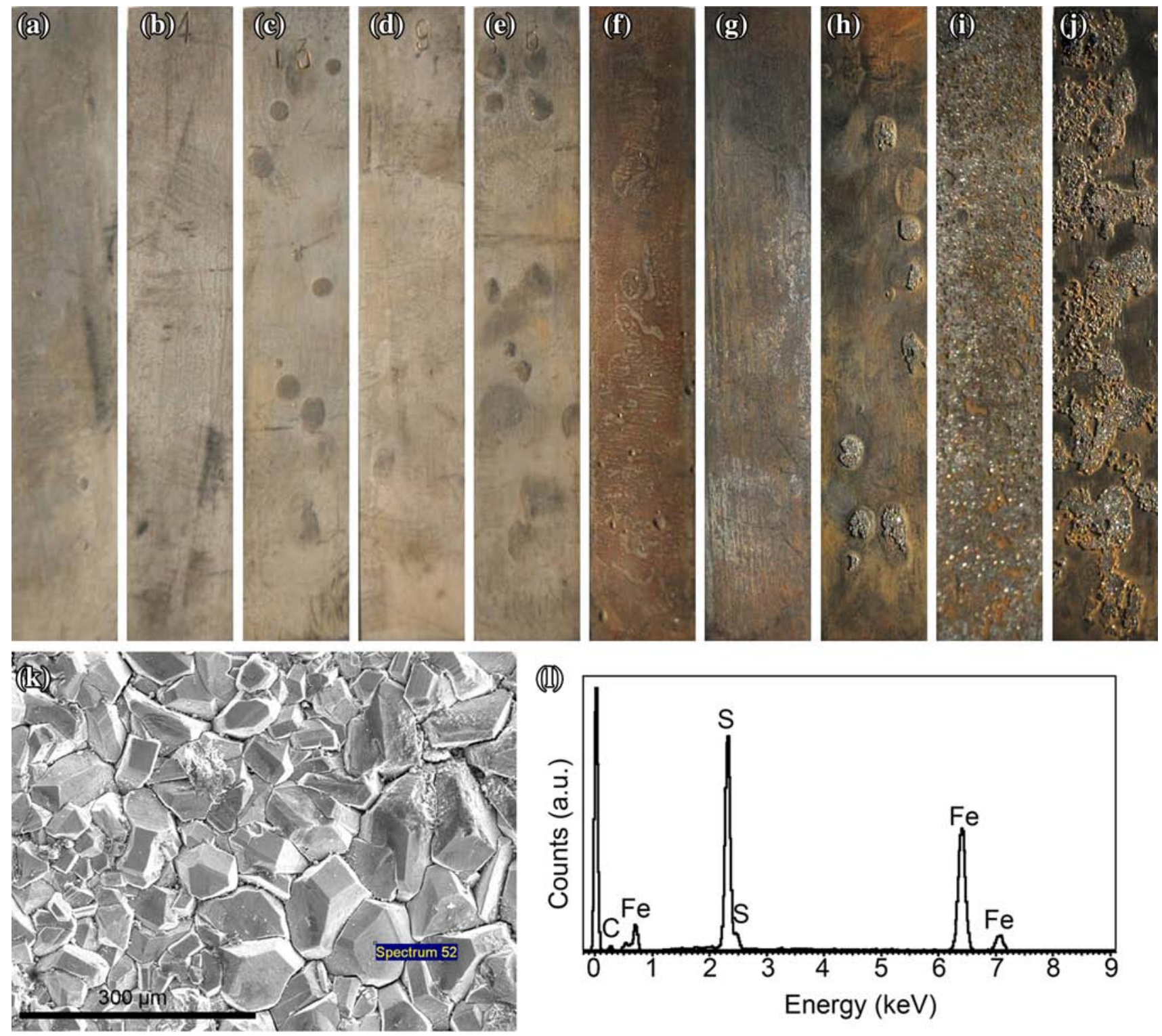

Fig. 4 Corrosion morphologies of the specimens and EDS analysis result: X70 a, X80 b, X90 c, X90-C d, X100 e steels subjected to standard test; X70 f, X80 g, X90 h, X90-C i, X100 j steels subjected to severe test; SEM image of the corrosion products on X90-C steel surface k; EDS result of the position as denoted in Fig. $4 \mathrm{k} \mathbf{l}$ 
Table 4 Hydrogen-induced cracking parameters of the steels

\begin{tabular}{|c|c|c|c|c|c|c|c|c|}
\hline \multirow[t]{2}{*}{ Steel } & \multicolumn{4}{|l|}{ Standard test } & \multicolumn{4}{|l|}{ Severe test } \\
\hline & Examined face & $R_{\mathrm{CS}}(\%)$ & $R_{\mathrm{CL}}(\%)$ & $R_{\mathrm{CT}}(\%)$ & Examined face & $R_{\mathrm{CS}}(\%)$ & $R_{\mathrm{CL}}(\%)$ & $R_{\mathrm{CT}}(\%)$ \\
\hline \multirow[t]{4}{*}{ X70 } & 1 & 0 & 0 & 0 & 1 & 0 & 0 & 0 \\
\hline & 2 & 0 & 0 & 0 & 2 & 0 & 0 & 0 \\
\hline & 3 & 0 & 0 & 0 & 3 & 0 & 0 & 0 \\
\hline & Average & 0 & 0 & 0 & Average & 0 & 0 & 0 \\
\hline \multirow[t]{4}{*}{$\mathrm{X} 80$} & 1 & 0 & 0 & 0 & 1 & 0.03 & 11.4 & 0.3 \\
\hline & 2 & 0 & 0 & 0 & 2 & 0 & 0 & 0 \\
\hline & 3 & 0 & 0 & 0 & 3 & 0 & 0 & 0 \\
\hline & Average & 0 & 0 & 0 & Average & 0.01 & 3.8 & 0.1 \\
\hline \multirow[t]{4}{*}{ X90 } & 1 & 0.3 & 60.9 & 1.9 & 1 & 1.2 & 67.0 & 3.1 \\
\hline & 2 & 0.1 & 35.8 & 0.7 & 2 & 1.1 & 39.1 & 3.4 \\
\hline & 3 & 0.2 & 22.3 & 0.7 & 3 & 0.1 & 13.1 & 0.9 \\
\hline & Average & 0.2 & 39.7 & 1.1 & Average & 0.8 & 39.7 & 2.5 \\
\hline \multirow[t]{4}{*}{ X90-C } & 1 & 0.06 & 31.6 & 0.4 & 1 & 0.02 & 20.9 & 0.08 \\
\hline & 2 & 0 & 0 & 0 & 2 & 0.2 & 65.0 & 0.3 \\
\hline & 3 & 0.2 & 66.5 & 0.8 & 3 & 0.02 & 22.4 & 0.08 \\
\hline & Average & 0.03 & 32.7 & 0.4 & Average & 0.08 & 36.1 & 0.15 \\
\hline \multirow[t]{4}{*}{ X100 } & 1 & 0.7 & 90.3 & 3.8 & 1 & 0.6 & 104.1 & 2.8 \\
\hline & 2 & 0.4 & 91.3 & 1.4 & 2 & 0.6 & 143.2 & 2.7 \\
\hline & 3 & 0.05 & 32.5 & 0.1 & 3 & 3.7 & 167.5 & 10.7 \\
\hline & Average & 0.38 & 71.4 & 1.8 & Average & 1.6 & 138.3 & 5.4 \\
\hline
\end{tabular}
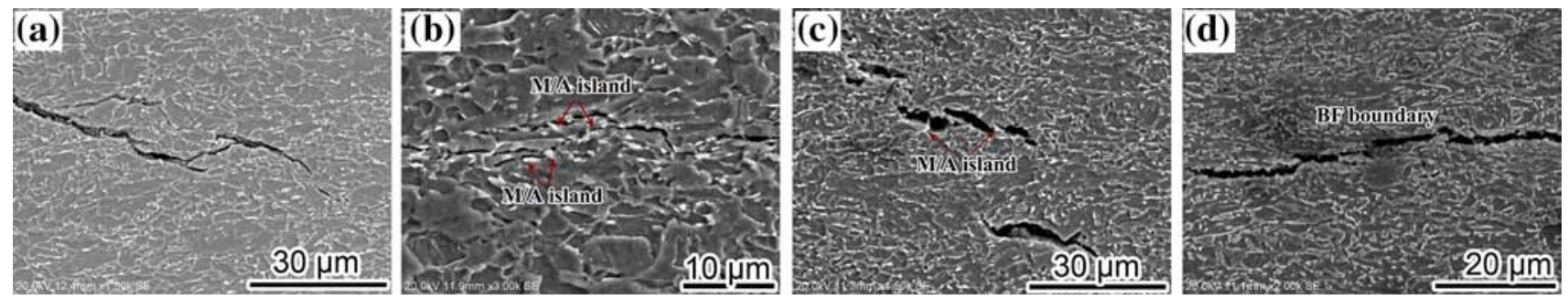

Fig. 5 HIC propagation path for the experimental steels: a X80 steel subjected to severe test, b X90 steel subjected to standard test, c X90-C steel subjected to standard test, d X100 steel subjected to severe test

the X80 steel exhibited lower HIC parameters, and only one crack was found on all examined surfaces. The observed cracks for the X80 steel showed that the propagation path was transgranular and agreed with the tortuous mode, indicating that the steel possessed excellent HIC resistance (Fig. 5a). However, for the X90 steel, HIC was seen to propagate along the interface between the $\mathrm{M} / \mathrm{A}$ island and the ferrite matrix, as indicated by arrows in Fig. 5b, c. For the X100 steel with a BF-dominated microstructure, HIC propagated mainly along the band-like bainitic ferrite boundary, as shown in Fig. 5d. Since BF for pipeline steel is one of the relatively harder phases, it can be a preferential path under HIC propagation.

\subsection{Sulfide Stress Corrosion Cracking}

Table 5 shows the results of SSC test of X80, X90 and $\mathrm{X} 90-\mathrm{C}$ steels. It can be seen that the time-to-failure increases with the decrease in load for the X90 and X90-C steels, evidently indicating that higher load makes SSC to more easily occur. For X80, however, it did not fracture after $720 \mathrm{~h}$ even at the $90 \%$ YS load, showing an excellent SSC resistance. In addition, X90 exhibited lower SSC susceptibility than X90-C. The cross sections of the fractured specimens after SSC test were examined by SEM. Figure 6 shows the typical SSC cracking behavior of X90$\mathrm{C}$ at $80 \%$ yield strength. The SSC crack propagated 
Table 5 Results of SSC examination for X80, X90 and X90-C steels

\begin{tabular}{lllll}
\hline Steel & YS (MPa) & UTS (MPa) & $\begin{array}{l}\text { Loading stress } \\
\text { (MPa) }\end{array}$ & $\begin{array}{l}\text { Duration } \\
\text { time }(\mathrm{h})\end{array}$ \\
\hline X80 & 620 & 720 & $496(80 \%$ YS $)$ & $>720$ \\
& & & $558(90 \%$ YS $)$ & $>720$ \\
X90 & 657 & 729 & $526(80 \%$ YS $)$ & 479 \\
& \multirow{2}{*}{6} & \multirow{2}{*}{726} & $591(90 \%$ YS $)$ & 203 \\
X90-C & 690 & & $552(80 \%$ YS $)$ & 335 \\
& & & $621(90 \%$ YS $)$ & 164 \\
\hline
\end{tabular}

perpendicular to the applied stress. Mainly two parts can be seen on the fractographs, quasi-cleavage fracture induced by SSC and ductile fracture caused by applied stress. The main SSC crack propagated perpendicular to the applied stress. Large size M/A islands were one of the main potential sites for surface crack formation. The stress concentration at the interface between M/A island and matrix would give rise to crack nucleation and subsequent propagation, and the explanation will be presented later in detail.

\section{Discussion}

Both HIC and SSC of the pipeline steels in $\mathrm{H}_{2} \mathrm{~S}$-containing environments can be explained by the theory of hydrogen embrittlement (HE). HE process generally consists of several steps [19], as shown in Fig. 7: (1) evolution of hydrogen in the environment; (2) hydrogen absorption on the steel surface; (3) diffusion of hydrogen into steel; (4) accumulation of hydrogen atoms at potential sites (inclusions, grain boundary, large size M/A islands and precipitated carbides, etc.); (5) initiation of cracking by internal pressure of hydrogen gas and propagation of the crack.

In general, corrosion on the steel surface produces hydrogen atoms. These atoms will combine together to form

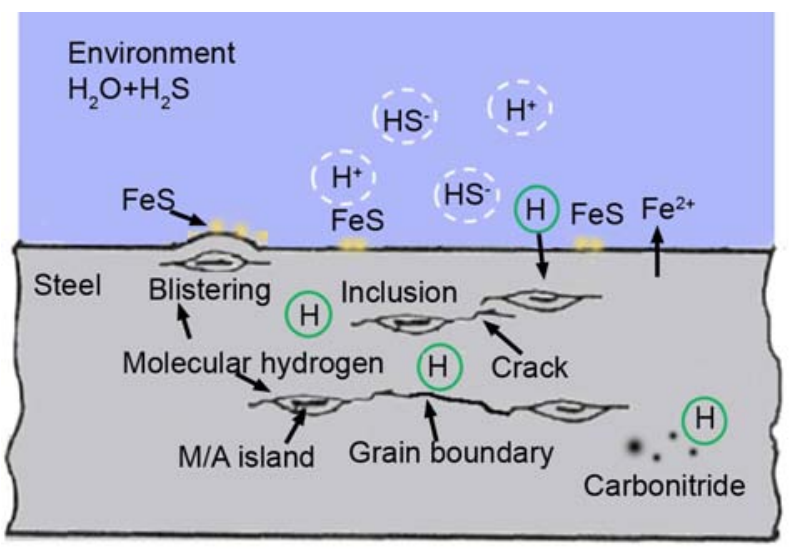

Corrosion reactions

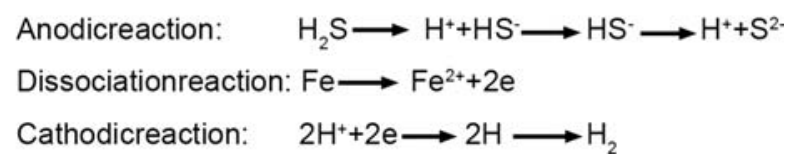

Fig. 7 Schematic diagram showing the behaviors of hydrogen in the steels

hydrogen gas. Some of the hydrogen gas will overflow to the environment, and the other will enter into the steel matrix [20]. However, hydrogen sulfide as a poison reagent retards the recombination reaction of hydrogen atoms to molecular hydrogen [21, 22], and this poisonous effect accelerates diffusion of atomic hydrogen into the steel. Internal pressure theory of HE based on hydrogen accumulation proposed by Zapffe et al. [23] can be used to explain the HIB cracking in Fig. 4. When the hydrogen atoms diffuse into the steel, they are trapped by potential sites. As mentioned above, all the experimental steels were examined carefully, and no evident inclusion was found because of the clean melting; thus, the effect of the inclusions was negligible. Moreover, it is well known that the fine precipitates, such as carbides, belong to the nonsaturated hydrogen traps which cannot pile up gas pressure [24]. Therefore, the larger-size M/A islands and the grain
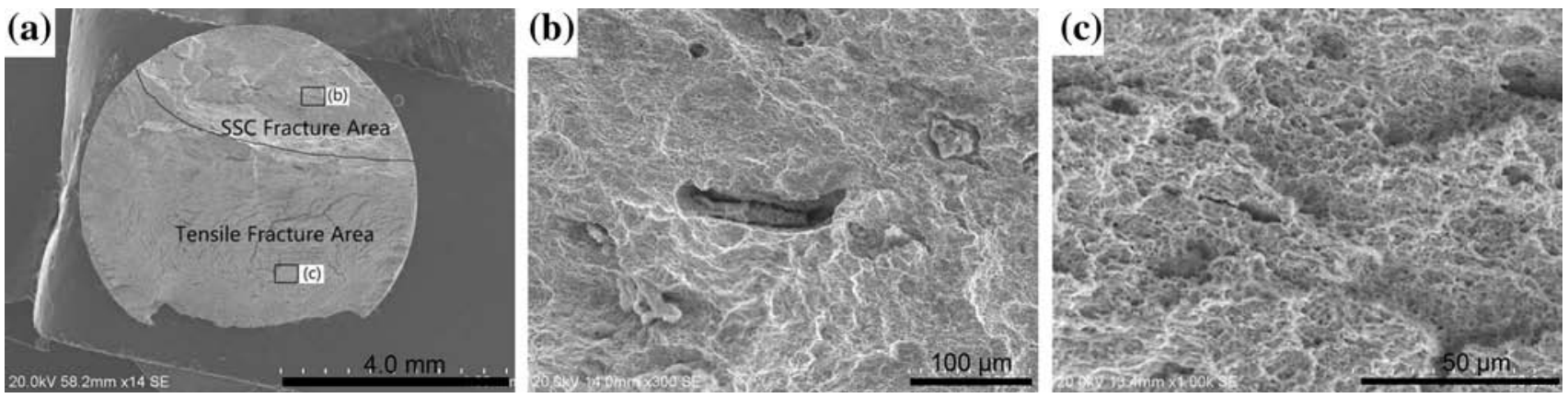

Fig. 6 Fractographs of SSC fracture at $80 \%$ YS loading of X90-C steel: a macrograph, b magnified image of the denoted area in Fig. 6a, c magnified image of the denoted area in Fig. $6 \mathrm{a}$ 
boundaries were responsible for the accumulation of the hydrogen atoms. The X70 and X80 steels exhibited an assemblage of interwoven non-parallel ferrite laths and finer dispersed M/A islands, which can be expected to act as hydrogen traps to modify the redistribution of hydrogen uniformly (Fig. 3a, b). Figure 8 shows the TEM observation results of X70 and X80 steels, which confirm that the X70 and X80 steels exhibit finer microstructure and highdensity tangled dislocations, which benefit for the $\mathrm{H}_{2} \mathrm{~S}$ resistance [5]. In contrast, the X90 had larger-size M/A islands (Fig. 3c). In order to identify the M/A island clearly, a special method was used.

Figure 9 shows the optical images of the X80 and X90 steels etched by Lapara reagent [26], in which the white phase is M/A islands and the ferrite matrix looks gray. Three images were studied for the two steels, and it was found, using Image Pro Plus analysis software, that the volume fractions of the M/A islands in the X80 and X90 steels were 7.6 and $14 \%$, respectively. Figure 10 provides the average size distribution of $\mathrm{M} / \mathrm{A}$ islands in the $\mathrm{X} 80$ and X90 steels. It is noted that the X80 steel has finer M/A islands compared to X90 steel. In a way, the stress concentration at the interface between M/A island and the ferrite matrix gives rise to the accelerated diffusion of hydrogen atoms. The work of Chen et al. showed that [25] the larger-size M/A islands came to a greater stress concentration. Therefore, more hydrogen atoms will be accumulated. As a result, the crack would be initiated at the interface between M/A island and ferrite matrix (Fig. 5b, c) if hydrogen concentration reached the critical value. Meanwhile, the localized stress gradient caused by the pressure of hydrogen gas would accelerate diffusion of hydrogen atoms further. Obviously, when the internal pressure reached the ultimate tensile strength of the steel, the cracking occurred. It can be easily understood that HIB would be found when the cracks were close to the surface of the steel. In addition, it has been confirmed that the hydrogen concentration in steels mainly depends on the environmental factors, such as $\mathrm{H}_{2} \mathrm{~S}$ partial pressure and $\mathrm{pH}$ value in the test solution [27-30]. In the present experiment, as shown in Table 4, the CTR increased most with the decrease in $\mathrm{pH}$ value and the increase in duration time. This result is in agreement with the report of Kittel et al. [31].

It has been indicated in this study that the improvement in mechanical properties of the experimental steels is related to the slight microstructural change of acicular ferrite. The acicular ferrite is known to have a better $\mathrm{H}_{2} \mathrm{~S}$ resistance. However, the microstructure of $\mathrm{BF}$ in $\mathrm{AF}$, as shown in Fig. 3e, exhibits straight lath boundaries which usually act as a kind of traps of hydrogen. Hydrogen is apt to diffuse to these boundaries. When its amount reaches the critical value, the HIC crack will initiate and grow along the BF boundary (Fig. 5d). Therefore, the X100 steel showed the worst HIC resistance. This result is in agreement with the work of Park et al. [32], showing that the bainite could trap hydrogen quite efficiently and make the steel brittle.

It has been indicated from the result of Table 5 that SSC susceptibilities of X80, X90 and X90-C steels were subsequently decreased. The reasons for this are that, firstly, as mentioned above, the SSC failure of pipeline steel generally is believed to result from HE under a combination of the tensile stress and the corrosion. Unlike HIC, SSC occurs accompanied with an externally applied stress, which leads to hydrogen accumulation at the sites with highly localized stress. Thus, the applied load can increase SSC susceptibility by increasing the diffusible hydrogen content in the steel. Moreover, it has been confirmed that the X90 steel possesses larger and more M/A islands than the X80 steel. In this case, the stress concentration due to M/A islands was greater under action of smaller maximum applied stress. Accordingly, the time-to-failure was shorter under the same applied stress level. On the other hand,
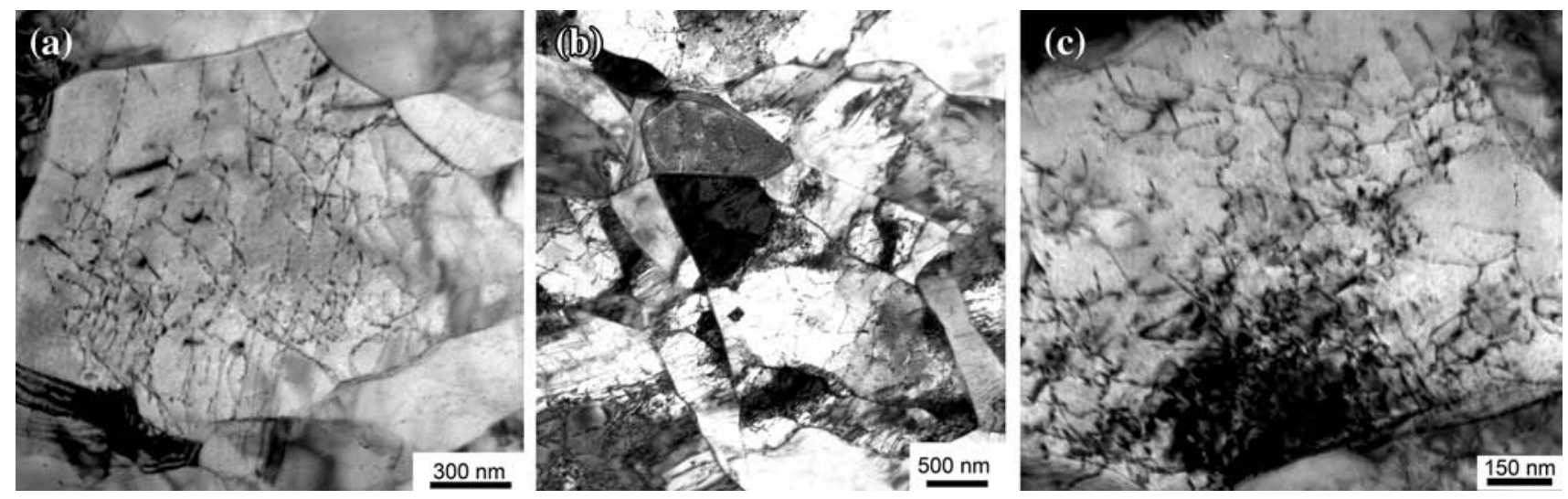

Fig. 8 TEM micrographs of X70 and X80 steels: a QF grain in X70 steel with high dislocation density, b acicular ferrite in X80 steel, c tangled dislocation in acicular ferrite 

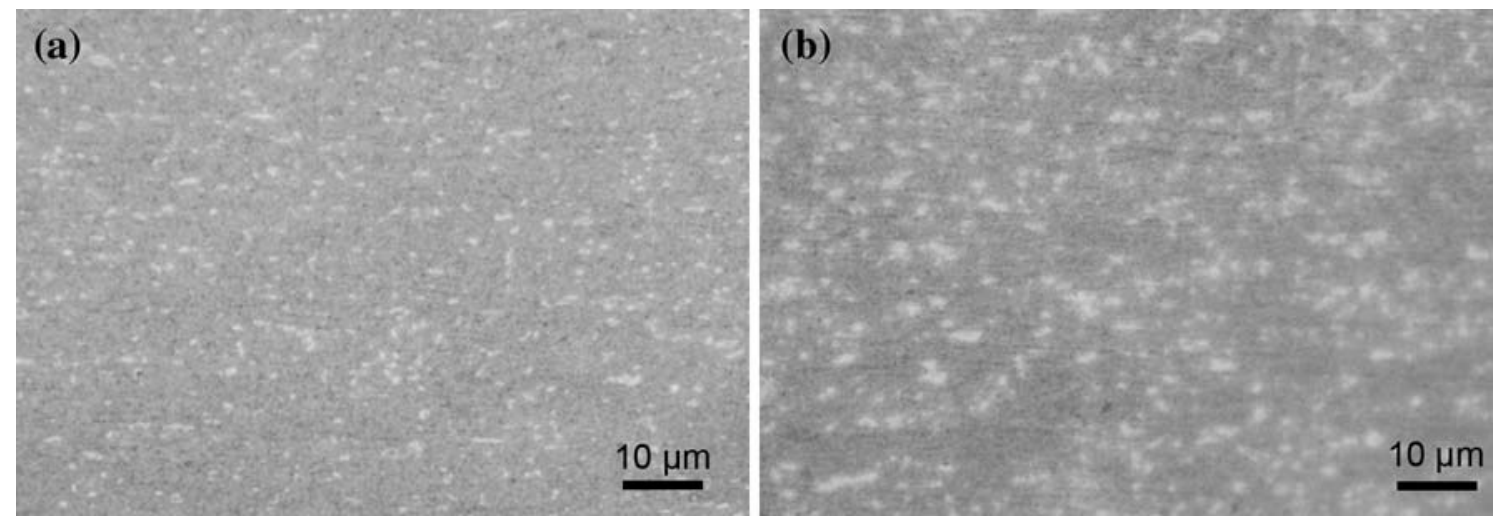

Fig. 9 Optical images of the experimental steels etched by Lapara reagent, a steel X80, b steel X90
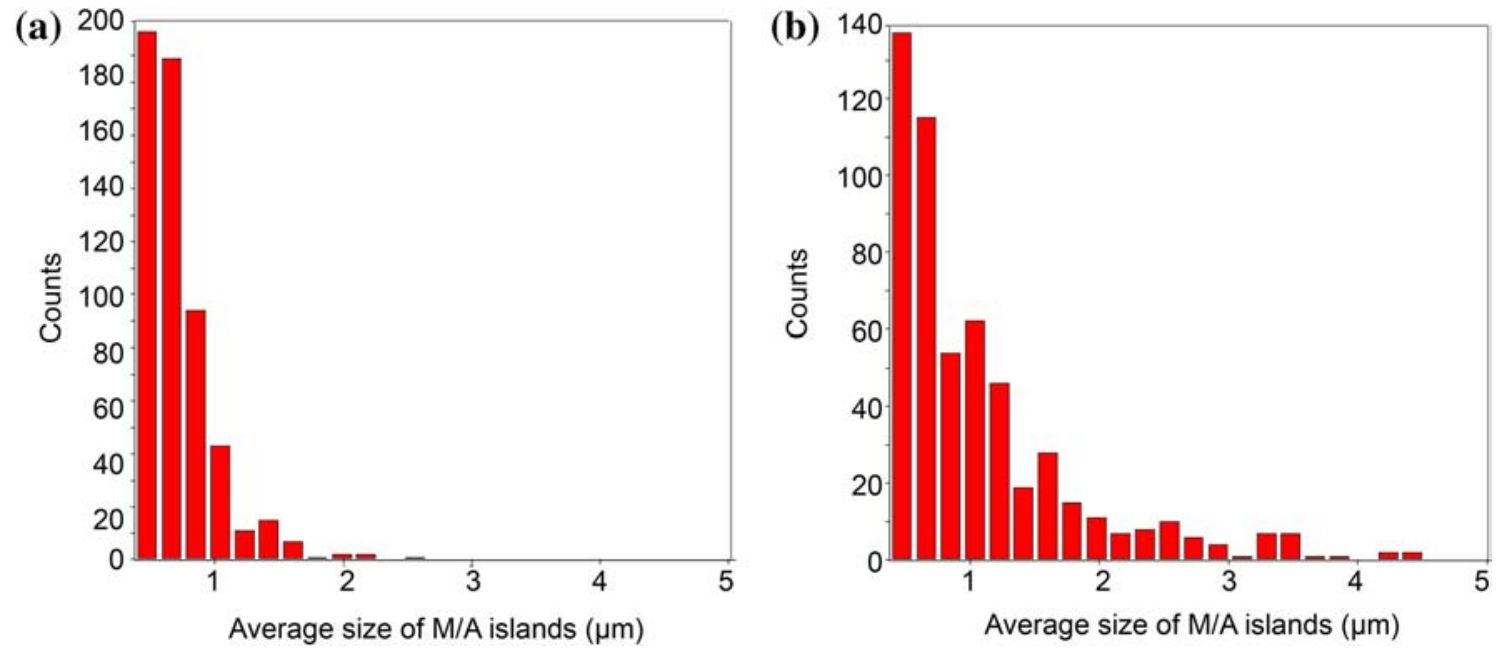

Fig. 10 Distributions of the average size of M/A inlands in X80 a, X90 b steels

M/A island as a hard phase in AF microstructure deteriorates the impact toughness [25], which further weakens the SSC resistance. This may be the reason that the X90-C steel had better HIC resistance but poor SSC resistance compared to X90 steel. Evidence of SSC-caused HE can be found from fracture characteristics of the cracked specimen (Fig. 6). Hydrogen diffusion can be strongly driven by the applied stress in the specimen. The soluble hydrogen in $\alpha$-Fe could enlarge the lattice parameter of steels, which further accelerates the hydrogen accumulation under the applied stress. In addition, hydrogen is easily transported to the triaxiality of stress at the interface between the ferrite and M/A islands, which induces cracking. The crack propagates until the ligament of the specimen could not hold the applied stress any longer. In this case, the specimen was broken mechanically into two parts by ductile fracture, as shown in Fig. 6c.

The present study has directly compared the behaviors of $\mathrm{H}_{2} \mathrm{~S}$ resistance of the steels with different strength grades. However, it is difficult to balance the $\mathrm{H}_{2} \mathrm{~S}$ resistance and high strength. The hard phases such as M/A islands and the BF will be presented in the high-strengthgrade pipeline steel, and hard phase is sensitive to HIC and SSC. In the present study, the hydrogen-induced cracks incubated and expanded along the larger-size M/A island or the lath boundary between different BFs. The results implied that both minimization the size of the M/A island and reduction in amount of the BF are effective ways to increase the $\mathrm{H}_{2} \mathrm{~S}$ resistance of the pipeline steel.

A non-quench aging process is proposed by Zhao et al. [24] to provide higher strength combined with more excellent SSC resistance. This process is attributed to additional precipitation in the ferrite region of nanometer-scale carbonitrides, which provide dispersion strengthening and beneficial hydrogen traps. However, the strength grade is less than X100. Thus, a new method, including composition optimization, processing parameters of TMCP and hydrogen trap controlled, may be proposed to realize the 
combination of high strength grade with better $\mathrm{H}_{2} \mathrm{~S}$ resistance in the future. This needs further research and is out of the present investigation.

\section{Conclusions}

1. The susceptibility of the experimental pipeline steels to HIC increased with the strength grade; the X70- and X80-grade pipeline steels had better HIC resistance, while X90- and X100-grade pipeline steels were relatively worse.

2. Hydrogen-induced blister (HIB) was observed on the surfaces of the X90, X90-C and X100 steels, and the density of HIB on the steel surface was increased with decreasing $\mathrm{pH}$ value for a given-grade pipeline steel.

3. HIC was found in the experimental steels to initiate and grow along the interface between large size M/A island and the ferrite matrix, and the straight lath boundaries of $\mathrm{BF}$ were responsible for the worst HIC resistance of the X100 steel.

4. The X80-grade steel showed the best SSC resistance because of the typical acicular ferrite microstructure and finer $\mathrm{M} / \mathrm{A}$ island size, and the large size M/A islands played an important role in the SSC susceptibility for the high-strength-grade pipeline steel.

Acknowledgments This work was financially supported by the National Key Technologies R\&D Program of China (No. 2011BAE25B03). Thanks are given to Prof. Wei Sha at the Queen's University Belfast for his efforts on this article.

\section{References}

[1] M.A. Al-Anezi, G.S. Frankel, A.K. Agrawal, Corrosion 55, 1101 (1999)

[2] K.T. Corbett, R.R. Bowen, C.W. Petersen, Int. J. Offshore Polar Eng. 14, 75 (2004)

[3] C. Mendibide, T. Sourmail, Corros. Sci. 51, 2795 (2009)

[4] M.C. Zhao, Y.Y. Shan, Y.H. Li, K. Yang, Acta Metall. Sin. 37, 1087 (2001). (in Chinese)

[5] M.C. Zhao, Y.Y. Shan, F.R. Xiao, K. Yang, Y.H. Li, Mater. Lett. 57, 141 (2002)
[6] S.U. Koh, H.G. Jung, K.B. Kang, G.T. Park, K.Y. Kim, Corrosion 64, 574 (2008)

[7] G.T. Park, S.U. Koh, H.G. Jung, K.Y. Kim, Corros. Sci. 50, $1856(2008)$

[8] B. Beidokhti, A. Dolati, A.H. Koukabi, Mater. Sci. Eng. A 507, 167 (2009)

[9] S.S. Nayaka, R.D.K. Misra, J. Hartmann, F. Siciliano, J.M. Gray, Mater. Sci. Eng. A 494, 456 (2008)

[10] Z. Shen, Y.H. Li, Y.Y. Shan, K. Liu, K. Yang, Acta Metall. Sin. 44, 215 (2008). (in Chinese)

[11] D. Hardie, E.A. Charles, A.H. Lopez, Corros. Sci. 48, 4378 (2006)

[12] M.A. Arafina, J.A. Szpunar, Mater. Sci. Eng. A 528, 4927 (2011)

[13] F. Huang, J. Liu, Z.J. Deng, J.H. Cheng, Z.H. Lu, X.G. Li, Mater. Sci. Eng. A 527, 6997 (2010)

[14] S.W. Thompson, D.J. Colvin, G. Krauss, Metall. Trans. A 21, $1493(1990)$

[15] F.R. Xiao, B. Liao, D.L. Ren, Y.Y. Shan, K. Yang, Mater. Charact. 54, 305 (2005)

[16] W. Wang, Y.Y. Shan, K. Yang, Acta Metall. Sin. 43, 578 (2007). (in Chinese)

[17] W. Wang, Y.Y. Shan, K. Yang, Mater. Sci. Eng. A 502, 38 (2009)

[18] M.C. Zhao, K. Yang, Y.Y. Shan, Metall. Mater. Trans. A 34, $1089(2003)$

[19] I. Chattoraj, Sadhana 20, 199 (1995)

[20] A. Traidia, M. Alfano, G. Lubineau, S. Duval, A. Sherik, Int. J. Hydrog. Energy 37, 16214 (2012)

[21] M. Al-Mansour, A.M. Alfantazi, M. El-boujdaini, Mater. Des. 30, 4088 (2009)

[22] D. Hejazi, A.J. Hap, N. Yazdipour, D.P. Dunne, A. Calka, F. Barbaro, E.V. Pereloma, Mater. Sci. Eng. A 551, 40 (2012)

[23] C.A. Zapffe, C.E. Sims, Trans. Am. Inst. Min. Metall. Pet. Eng. 145, 225 (1941)

[24] M.C. Zhao, K. Yang, Scr. Mater. 52, 881 (2005)

[25] J.H. Chen, Y. Kikuta, T. Araki, M. Yoneda, Y. Matsuda, Acta Metall. 32, 1779 (1984)

[26] R.M. Ale, J.M.A. Rebello, J. Charlier, Mater. Charact. 37, 89 (1996)

[27] W.K. Kim, S.U. Koh, B.Y. Yang, K.Y. Kim, Corros. Sci. 50, 3336 (2008)

[28] R.W. Revie, V.S. Sastri, G.R. Hoey, R.R. Ramsingh, D.K. Mak, M.T. Shehata, Corrosion 49, 17 (1993)

[29] T. Hara, H. Asahi, H. Ogawa, Corrosion 60, 1113 (2004)

[30] Z.Y. Liu, C.W. Du, X. Zhang, F.M. Wang, X.G. Li, Acta Metall. Sin. 26, 489 (2013). (Engl. Lett.)

[31] J. Kittel, V. Smanio, M. Fregonese, Corros. Sci. 52, 1386 (2010)

[32] G.T. Park, S.U. Koh, H.G. Jung, K.Y. Kim, Corros. Sci. 50, 1856 (2008) 